\title{
BILATERAL ABNORMAL COURSE OF BRACHIAL ARTERY RELATED WITH THE MEDIAN NERVE IN ARM: A CASE REPORT
}

\section{P. K. Senthil Ganesh *1, T. Naveen Sagar ${ }^{2}$.}

${ }^{1}$ Tutor, Department of Anatomy, Apollo Medical College, Chittoor, Andhra Pradesh, India.

${ }^{2}$ Assistant Professor, Department of Anatomy, Apollo Medical College, Chittoor, Andhra Pradesh, India.

\section{ABSTRACT}

Many formative variations of median nerve are known but this variant formation and course of median nerve is rare. A variant formation of median nerve was noted in the axilla and arm of a male cadaver, in the form of formation of median nerve behind the third part of axillary artery and brachial artery wind around median nerve. There may be compression of the nerve passing around the artery. This variation may be clinically important because symptoms of median nerve compression arising from similar variations are often confused with more common causes such as radiculopathy and carpal tunnel syndrome.

During routine dissection, one of the cadaver showed bilateral abnormal course of brachial artery in the arm. In the right arm: In the axilla, median nerve present posterior to the artery. In the left arm: brachial artery twisting around the median nerve. At the level of the neck of radius brachial artery dividing into radial and ulnar arteries in both side of upper limb.

KEY WORDS: Median Nerve. Brachial Artery, Axillary Artery, Lateral Root, Medial Root.

Address for Correspondence: P. K. Senthil Ganesh, Department of Anatomy, Apollo Medical College, Chittoor, Andhra Pradesh, India. E-Mail: senthilganesh52@gmail.com

Quick Response code

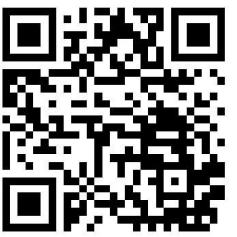

DOI: $10.16965 /$ ijar.2018.114
Journal Information

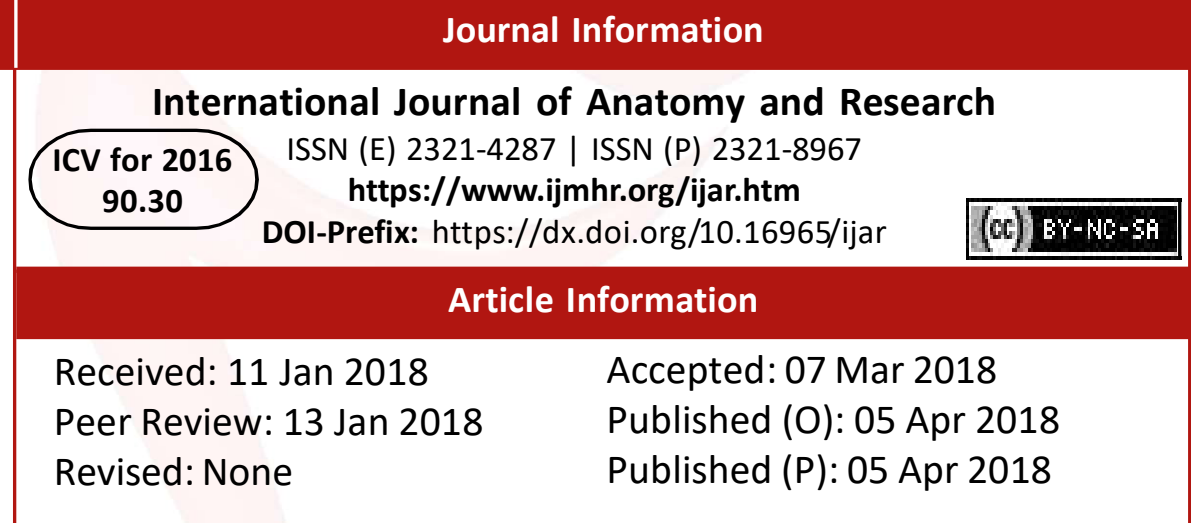

\section{INTRODUCTION}

Normally, Brachial artery begins as a continuation of axillary artery at the distal border of teres major. Median nerve crosses in front of the artery from lateral to medial side, at the middle of the arm. At the cubital fossa, it is crossed by the bicipital aponeurosis. At the level of neck of radius dividing into radial and ulnar arteries. Some formative variations of brachial artery are documented in the past. The present paper deals with one such formative variation of brachial a, in relation to median nerve.

\section{CASE REPORT}

During routine dissection classes of first MBBS students of AIMSR, Chittor, Andhra Pradesh. One of the cadaver showed bilateral abnormal course of brachial artery was observed in the right axilla and arm of a 50-year-old male cadaver.

Right arm: Figure1 showing, median nerve was formed by union of two roots, lateral root from lateral cord and medial root from medial cord. But two roots are united posterior to the third part of axillary artery instead of nerve uniting anterior to it. Then median nerve continues posterior to the brachial artery up to middle of arm. At the lower part of arm, brachial artery runs lateral to the median nerve. Distribution of median was as usual, so was that of brachial artery. At its termination, it bifurcates into radial and ulnar arteries. 
Fig. 1: BA- brachial artery, MuN- Musculocutaneous nerve, $\mathrm{MN}$ - median nerve.

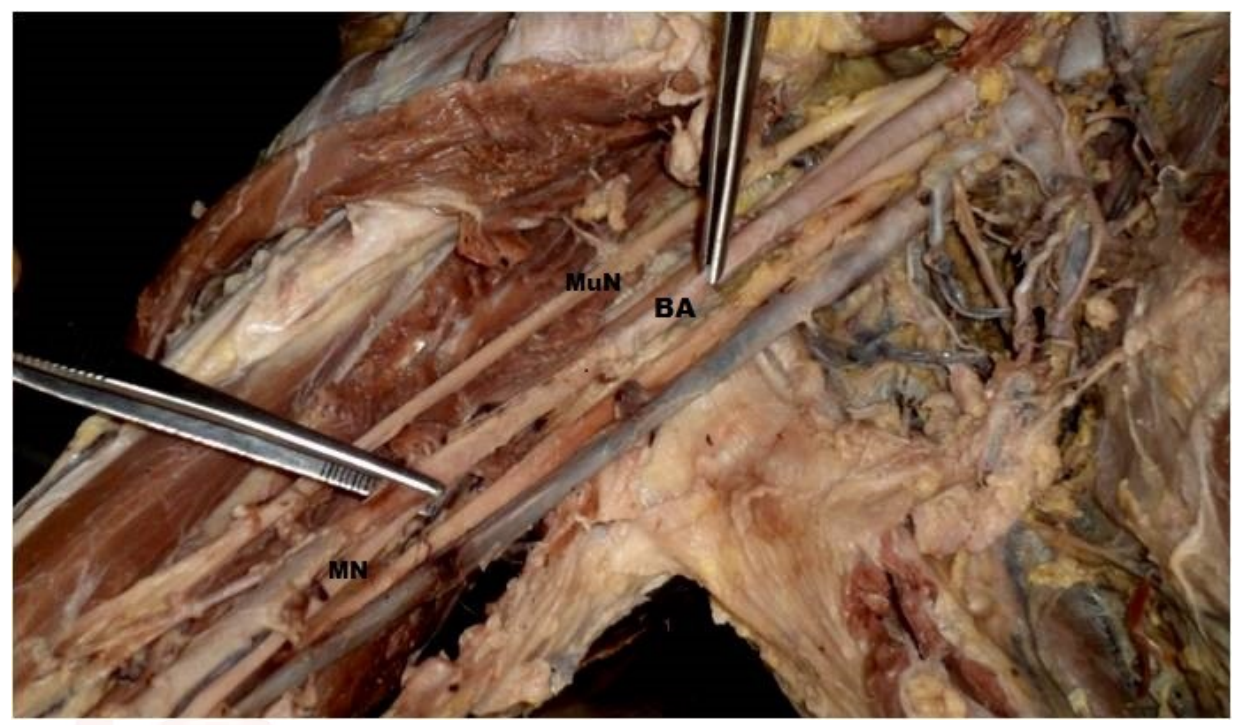

Fig. 2: BA- brachial artery, $\mathrm{MN}-$ median nerve.

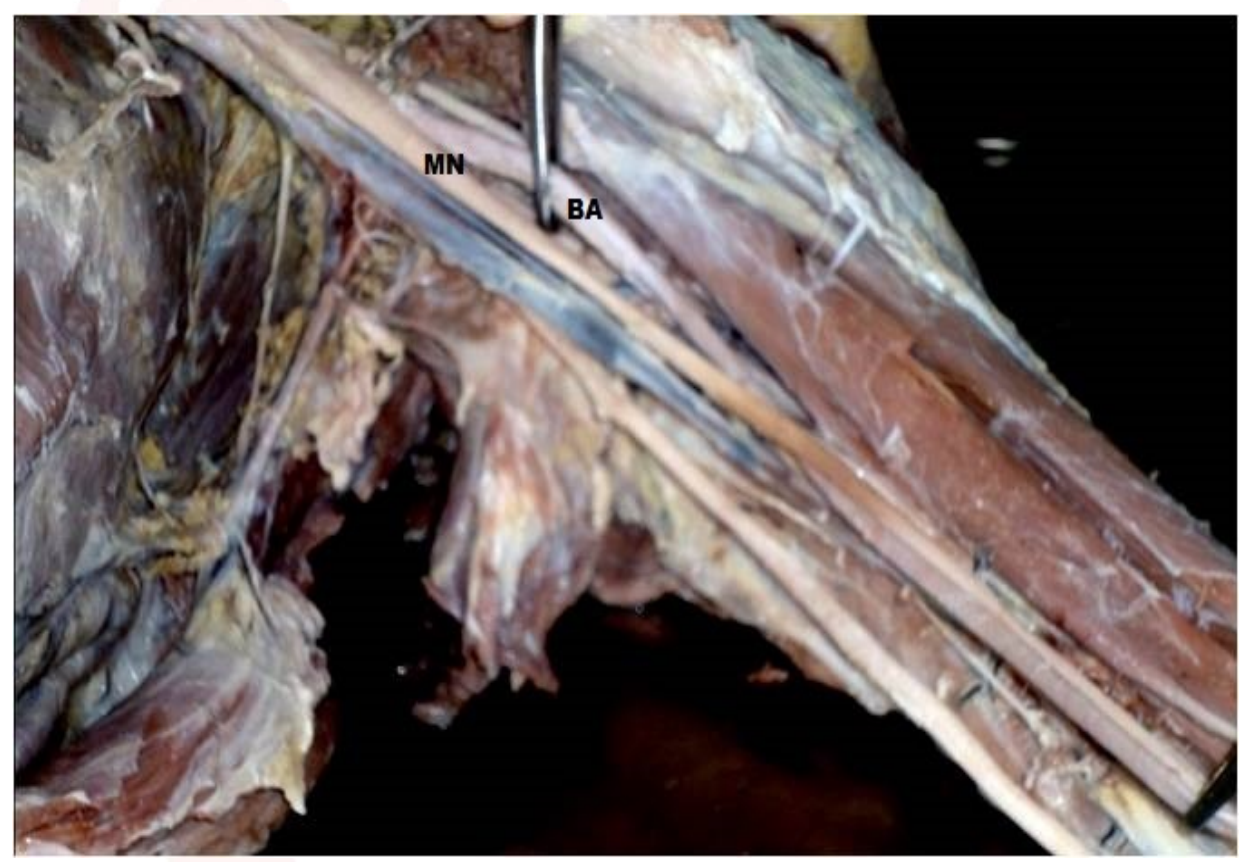

Fig. 3: BA- brachial artery, MNmedian nerve.

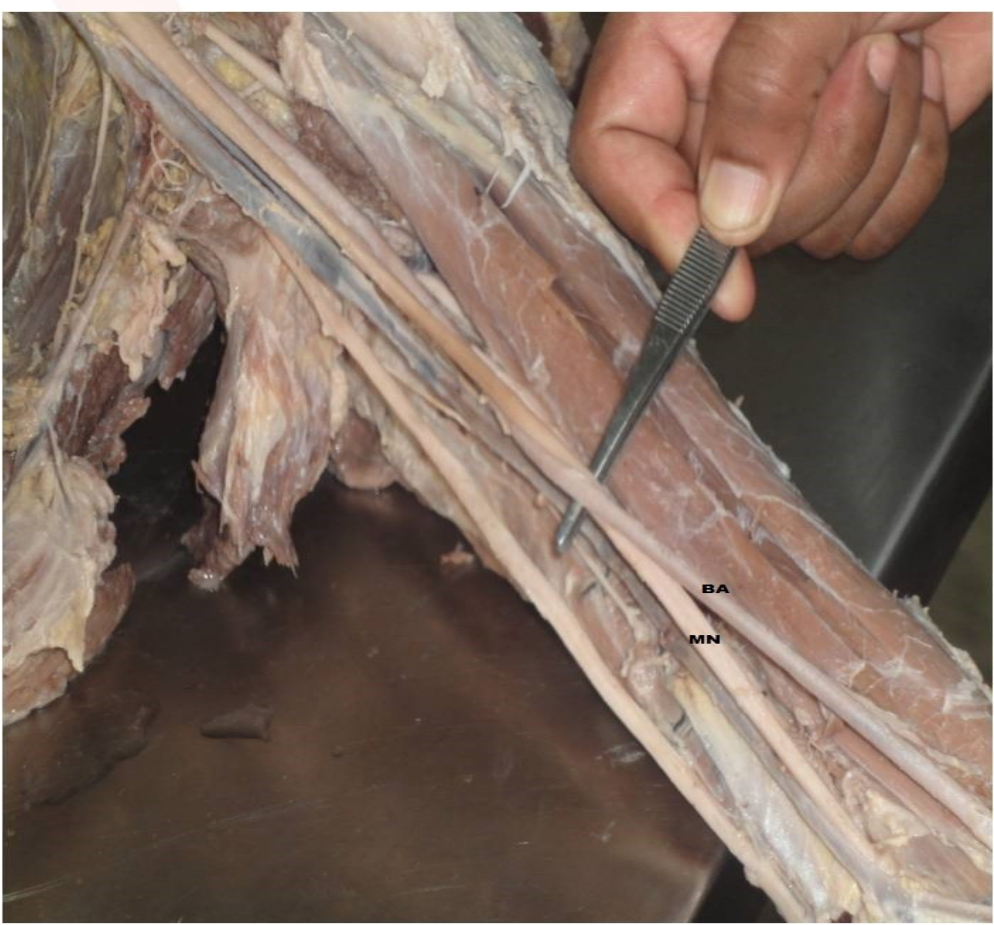


Left arm: Figure2: In the Axilla, median nerve root present anterior to the axillary artery. In the arm, mainly at the middle of arm, find the brachial artery winds around the median nerve. At first it runs posteromedial and then winds around anteriorly, then runs lateral to the median nerve in the lower part of arm. Figure3 showing, unusually artery winds around the median nerve. None of the article reported this type of variation. It may produce the compression of median nerve by brachial artery.

\section{DISCUSSION}

The formation of the median nerve posterior to the third part of axillary artery is rare and it is not reported in bilateral axillary dissections of 172 cadavers by Pandey and Shukla [1]. In 4.7\%, both roots of the median nerve were joined on medial side of the axillary artery to form a median nerve, which traveled medial to the artery in their study. In $2.3 \%$, the roots of the median nerve did not join and both traveled separately anteromedial to the axillary and brachial arteries in the study of the above authors [1].

A somewhat similar picture was reported by Chitra: in one case where the medial root of median nerve would be compressed between axillary and anterior circumflex humeral arteries [2]. Also Haviarova et al. have reported a case in which the formation of median nerve occurred behind the axillary artery on the right side [3]. This type of variation of formation of median nerve and also that of branching of axillary artery are mentioned by Bergman et al. [5,6].

The median nerve may be compressed at its formation in the present case between the axillary artery and the common trunk. Alternatively the third part of axillary artery may be compressed at the site of its branching by the upward fork of formation of median nerve. So, this case report is an example of high median nerve entrapment as well as axillary artery compression. A rare variation of entrapment of the medial root of median nerve between the axillary artery and its variant branch was reported by Vijaya et al. [7]. The knowledge of the high median nerve entrapment is important for the physicians. Also the knowledge of these types of variations is more important

\section{CONCLUSION}

Variations in formation of median nerve are reported. Knowledge of the variations, especially in relation to a neighboring artery will be of great help to understand the cause and effects of a lesion, both in the nerve and the artery. It will also be helpful to take necessary preoperative precautions and formulate a strategy while planning a surgery in the region.

Embryological explanation for such variations must be sought to understand specific patterns of nerve arrangement and possible associated variations in other nerves and tissues. In the left side of arm, brachial artery winds around the median nerve. Because of this pattern of arterial course compress the median nerve and the brachial artery, this may leads to cause Volkmann's ischemic contracture and ape thumb deformity.

\section{Conflicts of Interests: None}

\section{REFERENCES}

[1]. Pandey SK, Shukla VK. Anatomical variations of the cords of brachial plexus and the median nerve. Clin Anat. 2007;20:150-156.

[2]. Chitra R. A rare variant formation of the median nerve: a case report. The Internet Journal of Neurology. 2007;8(2).

[3]. Haviarova Z, el Falougy HA, Killingerova A. Atypical course of the median nerve. Bratisl Lek Listy. 2001;102:372-373.

[4]. Bergman R.A, Afifi A.K, Miyauchi R. Illustrated encyclopedia of human anatomic variations: Part III: Nervous system: Plexuses: Median Nerve. http:// www.anatomyatlases.org/AnatomicVariants/ NervousSystem/Text/MedianNerve.shtml (accessed March 2010)

[5]. Bergman R.A, Afifi A.K, Miyauchi R. Illustrated encyclopedia of human anatomic variations: Opus II: Cardiovascular system: Arteries: Upper limb: Axillary artery. http://www.anatomyatlases.org/ AnatomicVariants/Cardiovascular/Text/Arteries/ Axillary.shtml (accessed March 2010)

[6]. Vijaya PS, Vollala VR, Mohandas R, Shetty S. A rare entrapment of medial root of median nerve between axillary artery and its anomalous branch. The Internet Journal of Neurology. 2006;5(2).

How to cite this article: P. K. Senthil Ganesh, T. Naveen Sagar. BILATERAL ABNORMAL COURSE OF BRACHIAL ARTERY RELATED WITH THE MEDIAN NERVE IN ARM: A CASE REPORT. Int J Anat Res 2018;6(2.1):5076-5078. DOI: 10.16965/ijar.2018.114 